\title{
O MEDIEVALISMO GALEGO-PORTUGUÊS: UM IDEAL DE VIDA
}

\section{Galego-portuguese medievalism: an ideal of life}

\author{
Prof. Dr. Fernando Ozorio Rodrigues \\ Diretor do Núcleo de Estudos Galegos da UFF \\ ORCID: https://orcid.org/0000-0002-7135-7555
}

Email: ozoriouff@gmail.com

Recebido em: 10/06/2020

Resumo: O objetivo deste texto é prestar uma homenagem à Profa. Dra. Maria do Amparo Tavares Maleval, com destaque para a atuação da homenageada à frente do Núcleo de Estudos Galegos da Universidade Federal Fluminense. Ressaltam-se as iniciativas de Maria do Amparo como criadora do NUEG, além de incentivadora e organizadora de atividades acadêmicas, com ênfase na divulgação da língua, da literatura e da cultura galega. Foram jornadas, seminários, palestras, cursos de extensão, edição de CDs, e publicação de livros e periódicos. Entre esses trabalhos, salienta-se a publicação do periódico Estante Medieval, coleção que se propõe tornar acessíveis aos estudiosos da Idade Média fontes primárias medievais e teses doutorais, bem como outros estudos considerados relevantes sobre o medievo. Por fim, dá-se ênfase ao volume 11 da coleção, de autoria de Maria do Amparo, cujo trabalho de revisão e editoração ela não conseguiu concluir por ter adoecido, vindo a falecer.

Palavras-chave: homenagem; cultura galega; coleção Estante Medieval.

Abstract: The aim of this text is to pay tribute to Profa. Dra. Maria do Amparo Tavares Maleval, with emphasis on the performance of the honoree at the head of the Galician Studies Center of the Fluminense Federal University. Maria do Amparo's initiatives as the creator of NUEG, as well as an incentive and organizer of academic activities, with emphasis on the dissemination of the language, literature and the galega culture, stand out. There were days, seminars, lectures, extension courses, $\mathrm{CD}$ editing, and publication of books and periodicals. Among these works, we highlight the publication of the journal Shelf Medieval, a collection that aims to make accessible to scholars of the Middle Ages medieval primary sources and doctoral theses, as well as other studies considered relevant on the media. Finally, there is emphasis on volume 11 of the collection, authored by Maria do Amparo, whose review and publishing work could not conclude because she got sick, coming to death.

Keywords: tribute; Ghastly culture; Medieval Bookcase collection. 
A minha relação de convivência acadêmica mais próxima com Maria do Amparo Tavares Maleval data de 1994, quando ela solicitou ao Departamento de Letras Clássicas e Vernáculas da Universidade Federal Fluminense autorização para criar o Núcleo de Estudos Galegos (NUEG), convidando-me para ser o Vice-Diretor do Núcleo.

O NUEG foi instituído pela Norma de Serviço 400/94, assinada pelo Magnífico Reitor José Raimundo Martins Romeo, em 10 de janeiro de 1994. Nesse mesmo ano foi assinado o Convênio de Colaboração entre a Xunta de Galicia e a UFF, com a finalidade de fomentar e realizar atividades para a divulgação da língua, da literatura e da cultura galega em geral, no âmbito da UFF. O acordo de cooperação continua em vigor, sendo renovado todo ano.

A rigor, a atuação de Maria do Amparo na UFF como professora do Departamento de Letras Clássicas e Vernáculas, no Setor de Literatura Portuguesa, sempre foi caracterizada por seu interesse em ministrar as disciplinas relacionadas ao medievalismo. Tanto que a sua Tese de Doutorado, na USP, em 1982, sob orientação do Professor Massaud Moisés, teve como tema a retórica de Fernão Lopes, cronista do século XV do reino de Portugal.

Como atividades embrionárias do projeto de criação do NUEG, em 1991, sob a coordenação de Maria do Amparo, no Instituto de Letras da UFF, foram realizados importantes eventos acadêmicos relacionados à cultura galega. No segundo semestre daquele ano, foi oferecido um curso de extensão intitulado Língua e Cultura Galega, ministrado pela professora Teresa Candinho Barreiro, da Universidade de Santiago de Compostela. No encerramento do curso, foram realizadas as Jornadas UFF de Cultura Galega, cujas conferências foram publicadas em Cadernos de Letras 5 -Aspectos da Cultura Galega, publicação do Instituto de Letras da UFF.

O dinamismo imprimido por Maria do Amparo à frente do NUEG produziu excelentes frutos não só para a divulgação da cultura galega, mas também na formação de pesquisadores interessados na literatura medieval galego-portuguesa. Como professora do Curso de Pós-Graduação da UFF, Maria do Amparo orientou várias Dissertações de Mestrado e Teses de Dourado e deu ensejo à criação de um círculo de pesquisadores voltados principalmente para os temas do medievalismo. 
O NUEG vem se dedicando a promover variados eventos acadêmicos, sempre voltado para a divulgação da língua, literatura e cultura galega. Em 1994, como complemento da criação do NUEG, foram realizadas as II Jornadas UFF de Cultura Galega.

A partir desse ano também passaram a ser oferecidos semestralmente cursos de extensão, tendo Maria do Amparo convidado inicialmente alguns professores de universidades galegas, entre eles Dr. Carlos Paulo Martinez Pereiro (Universidade da Coruña), Francisco Singul (Conselleria de Cultura da Xunta de Galicia), Maria Sol López (Universidade de Santiago de Compostela), Lydia Fontoira (Universidade de Santiago de Compostela), e ainda o poeta de ascendência galega Reynaldo Valinho Alvarez.

Os cursos de extensão continuaram a ser oferecidos com a média de um curso por semestre, ministrados por diversos professores convidados, entre os quais Beatriz Gradaílle, Xoán Carlos Lagares, Baltasar Pena Abal, Maria Belen Posada, Diego Bernal, Denis Vicente Rodrigues, Suzana Alvarez Martínez, Leonila Maria Murinelly, Erick Carvalho e Lucía Sande Sioba.

A meu convite, Maria do Amparo ofereceu um curso de extensão no $2^{\circ}$ semestre de 2016, intitulado A peregrinação a Santiago de Compostela.

Dedicou-se também o NUEG, sob a Direção de Maria do Amparo, à edição de CDs e publicações de livros e periódicos. Entre os CDs, gravados pelo Conjunto de Música Antiga da UFF, estão o CD Cânticos de amor e louvor e o CD MedievoNordeste; e gravado pelo conjunto Longa Florata da UFF o CD Annua Gaudia, a Música do Caminho de Santiago.

Quanto às publicações, à frente do NUEG, dedicou-se a Maria do Amparo a uma importante coleção, com o selo da EDUFF, intitulada Estudos Galegos, da qual foram publicados 5 números, o primeiro dos quais em 1996 e o último em 2007. Em cada número foram reunidos textos de muitos professores e pesquisadores sobre os mais diversos temas relacionados ao medievalismo e à cultura galega. Entre os convidados estão Leodegário de Azevedo Filho, Yara Frateschi Vieira, Lênia Márcia Mongelli, Reynaldo Valinho Alvarez, Dalma Nascimento, Nélida Piñon, Carlos Paulo Martinez Pereiro, Francisco Singul Lorenzo, Xoán Carlos Lagares, Edmundo Moure Rojas, 
Maximiano de Carvalho e Silva, Massaud Moisés, Ângela Vaz Leão, Maria Isabel Morán Cabanas e muitos outros. Destaco essa relação de colaboradores convidados para se ter uma ideia da dimensão dos contatos acadêmicos de Maria do Amparo, no Brasil e na Galícia, em especial.

Paralelamente a essa publicação, Maria do Amparo publicou e organizou várias outras obras, entre as quais Estudos Galegos Brasileiros (org.), Poesia Medieval no Brasil, Atas do III Encontro de Estudos Medievais da ABREM (org.), Atualizações da Idade Média (org.), Peregrinação e Poesia; Rastros de Eva (no Imaginário ibérico do século XII ao XVI) e Maravilhas de São Tiago: Narrativas do Liber Sancti Jacobi (Codex Calixtinus).

Em 1996, Maria do Amparo aposentou-se de suas atividades na UFF, mas continuou dirigindo o NUEG com todo o dinamismo. Em 2006, ela solicitou que eu assumisse a direção do NUEG. Ela já era professora da UERJ onde, em 1998, criara o Programa de Estudos Galegos (PROEG). Com uma proposta mais avançada, o PROEG funciona como um Leitorado Galego, com oferecimento de disciplinas eletivas no currículo dos alunos do Curso de Letras da UERJ. Para tanto, a Xunta de Galicia envia periodicamente um leitor que fica responsável pelas atividades do Leitorado, oferecendo as disciplinas e organizando eventos.

A partir de 2006, as duas instituições de estudos galegos, NUEG e PROEG, passaram a desenvolver várias atividades conjuntas, sob a orientação de Maria do Amparo, entre as quais a mais importante foi a coleção Estante Medieval, com o selo da EDUFF. A coleção se propõe tornar acessíveis aos estudiosos da Idade Média fontes primárias medievais e teses doutorais, bem como outros estudos considerados relevantes sobre o medievo.

Dessa coleção já foram publicados 10 números: As cantigas de Santa Maria: um estilo gótico na lírica ibérica medieval, de Bernardo Monteiro de Castro, 2006; As Cantigas de D. Joan Garcia de Guilhade e estudos dispersos, de Oskar Nobiling, organizada por Yara Frateschi Vieira, 2007; Reflexões sobre a Hagiografia Ibérica Medieval: um estudo comparado do Liber Sancti Jacobi e das vidas de santos de Gonzalo de Berceo, de Andréia Cristina Lopes, 2008; Monarquia e Igreja na Galiza na segunda metade do século VI - O modelo de monarca nas obras de Martinho de Braga dedicadas ao rei 
suevo, de Leila Rodrigues da Silva, 2008; Fernão Lopes e a retórica medieval, de Maria do Amparo Tavares Maleval, 2010; Cancioneiro d'El Rei Dom Denis e estudos dispersos, de Henry R. Lang, organizada por Lênia Márcia Mongelli e Yara Frateschi Vieira, 2010; Amadis de Gaula: entre as fendas dos códigos da Cavalaria e do Amor Cortês, de Leonila Maria Murinelly Lima, 2012; Os cavaleiros que fizeram as cantigas: aproximações às origens socioculturais da lírica galego-portuguesa, de José António Souto Cabo, 2013; Contos e histórias de proveito e exemplo, de Gonçalo Fernandes Trancoso, com introdução, estabelecimento de texto, glossário e notas de Fernando Ozorio Rodrigues, 2013; Gregório de Tours e a sociedade cristã na Gália dos séculos V e VI, de Edmar Checon de Freitas, 2015.

É importante destacar que todas essas publicações decorreram de convites feitos por Maria do Amparo aos respectivos autores e organizadores, em razão de sua extensa lista de contatos acadêmicos, além das inúmeras orientações de trabalhos e participação em bancas de avaliação de títulos de mestrado e doutorado. Outro dado a destacar é a periodicidade das publicações, a rigor uma por ano, sendo que em 2008 foram publicados dois números. O que demonstra o dinamismo do trabalho, sem perder o rigor da qualidade acadêmica e editorial, sempre uma enorme preocupação de Maria do Amparo.

Tive o prazer de dividir com ela a responsabilidade pela direção da coleção Estante Medieval. Posso testemunhar o enorme trabalho desenvolvido, desde a seleção da tese a ser publicada e do convite ao autor, até todo trabalho de revisão, editoração, licitação da gráfica e programação do lançamento. Muitas horas de trabalho, mas de enorme satisfação pelos resultados alcançados.

Os volumes 11 e 12 da coleção estão prontos. O número 11 é da Professora Maria do Amparo Tavares Maleval, intitulado O teatro medieval e seus congêneres em Santiago de Compostela (séculos XII e XIII), e o volume 12 é do Professor Henrique Marques Samyn e intitula-se A pastora e a alegoria: a invenção da pastorela alegórica - da lírica occitânica aos Carmina Burana e ao trovadorismo galegoportuguês. 
$\mathrm{Na}$ verdade, mantido o ritmo de produção dos 10 primeiros volumes, poderíamos estar com 15 números publicados. Porque material para publicação, teses e pesquisas sobre o medievo galego-português, não faltam, muitas aguardando vir à luz numa publicação com o selo de uma instituição rconhecida. E também não faltariam determinação e entrega para a produção dos livros.

Houve, entretanto, um problema que nos obrigou a reduzir o ritmo de trabalho e que gerou atraso na produção dos livros. Até 2015, eu e Maria do Amparo selecionávamos o trabalho a ser publicado, apresentávamos à Direção da Editora o projeto e, com a aprovação, tomávamos todas providências de revisão, editoração e licitação de gráfica. Com o livro pronto, o entregávamos à Editora para o lançamento. A partir de 2016, a Direção da EDUFF alterou a dinâmica de seleção e editoração de suas publicações. Apresentado o projeto, todo o trabalho de revisão, editoração e licitação da gráfica passou a ser feito pela própria Editora. Infelizmente, em que pese a qualidade e dedicação dos funcionários, para eles era muito difícil atender a toda a demanda de livros pelos quais a EDUFF se responsabilizava. O projeto do livro do Professor Henrique Samyn foi apresentado em 2016, e o livro só foi entregue pela gráfica à EDUFF em dezembro de 2020. Era para sair como número 11, mas, por erro de editoração, saiu como número 12 .

O projeto do livro de Maria do Amparo foi apresentado em 2018, mas infelizmente a professora faleceu sem ver o livro pronto. Em novembro do ano passado, ela recebeu os originais para fazer a última revisão e autorizar a editora a enviar para a gráfica. Não teve tempo. No início de dezembro foi hospitalizada em estado grave, internada em UTI, mas não resistiu: faleceu em 7 de janeiro de 2021.

Ainda em janeiro, a ditora entrou em contato comigo para saber que providência tomar com relação ao livro. Entrei em contato com a família, para saber se havia interesse de que o livro fosse publicado. Com o consetimento, assumi junto à EDUFF a responsabilidade de fazer a última revisão e encaminhar o livro para a gráfica. No final do mês de janeiro, completei a revisão e fiz o encaminhamento. A expectativa é que até o mês de junho já esteja pronto.

Este é um pequeno relato, de uma pequena área de atuação de Maria do Amparo. O currículo da professora é uma demonstração da enorme capacidade de trabalho e da profícua produção acadêmica que nos legou. Em muitas outras atividades e em muitos 
outros contatos pessoais e institucionais. Foi uma perda irreparável. Criou-se uma enorme lacuna na área de pesquisa relacionada ao medievalismo galego-português.

No texto que a Direção do NUEG divulgou lamentando o falecimento de nossa fundadora e sempre incentivadora, transcrevemos uma cantiga-pranto que o trovador Pero da Ponte compôs para o homenagear a Rainha Dona Beatriz, mãe de Afonso X, por ocasião do falecimento da soberana. Reproduzimos aqui a cantiga. Entendemos que a melhor forma de homenagear a professora Maria do Amparo Tavares Maleval é trazer uma voz da Idade Média que ela tão bem conhecia e amava.

Nostro Senhor Deus! Que prol vos tem ora por destroirdes este mund' assi?

Que a melhor dona que era i, nem houve nunca (vossa madre fora), levades end'? E pensastes mui mal daqueste mundo fals' e desleal: que, quanto bem aquesto mund' havia, todo lho vós tolhestes em um dia!

Que pouc' home por en prezar devia este mundo, pois bondad' i nom val contra morrer! E pois el assi fal, seu prazer faz quem per tal mundo fia: ca o dia que eu tal pesar vi, já, per quant' eu deste mund' entendi, por fol tenh' eu quem por tal mundo chora e por mais fol quem mais en' el[e] mora!

Em forte ponto e em fort[e] hora fez Deus o mundo, pois nom leixou i nẽum conort[o] e levou daqui a bõa rainha, que ende fora, dona Beatrix! Direi-vos eu qual: nom fez Deus outra melhor nem tal, nem de bondade par nom lh'acharia home no mundo, par Santa Maria! 